Article

\title{
Impact of Nisin and Nisin-Producing Lactococcus lactis ssp. lactis on Clostridium tyrobutyricum and Bacterial Ecosystem of Cheese Matrices
}

\author{
Hebatoallah Hassan ${ }^{1,2, *(\mathbb{D})}$, Daniel St-Gelais ${ }^{3}$, Ahmed Gomaa ${ }^{4}$ and Ismail Fliss ${ }^{1}$ \\ 1 STELA Dairy Research Center, Institute of Nutrition and Functional Foods, Université Laval, \\ Québec, QC G1V 0A6, Canada; ismail.fliss@fsaa.ulaval.ca \\ 2 Institute of Graduate Studies and Research, Alexandria University, Alexandria 21526, Egypt \\ 3 Food Research and Development Centre, Agriculture and Agri-Food Canada, \\ Saint-Hyacinthe, QC J2S 8E3, Canada; damilk83@hotmail.com \\ 4 National Research Center, Nutrition and Food Science Department, Cairo 12622, Egypt; \\ ahmed.el-sayed@mail.mcgill.ca \\ * Correspondence: hebatoallah.hassan.1@ulaval.ca; Tel.: +1-5813090202
}

check for updates

Citation: Hassan, H.; St-Gelais, D.; Gomaa, A.; Fliss, I. Impact of Nisin and Nisin-Producing Lactococcus

lactis ssp. lactis on Clostridium tyrobutyricum and Bacterial Ecosystem of Cheese Matrices. Foods 2021, 10, 898. https://doi.org/ 10.3390 /foods 10040898

Academic Editors: Paloma López and Maria Teresa Dueñas

Received: 15 March 2021

Accepted: 15 April 2021

Published: 19 April 2021

Publisher's Note: MDPI stays neutral with regard to jurisdictional claims in published maps and institutional affiliations.

Copyright: (c) 2021 by the authors. Licensee MDPI, Basel, Switzerland. This article is an open access article distributed under the terms and conditions of the Creative Commons Attribution (CC BY) license (https:// creativecommons.org/licenses/by/ $4.0 /)$.

\begin{abstract}
Clostridium tyrobutyricum spores survive milk pasteurization and cause late blowing of cheeses and significant economic loss. The effectiveness of nisin-producing Lactococcus lactis ssp. lactis 32 as a protective strain for control the C. tyrobutyricum growth in Cheddar cheese slurry was compared to that of encapsulated nisin-A. The encapsulated nisin was more effective, with $1.0 \log _{10}$ reductions of viable spores after one week at $30{ }^{\circ} \mathrm{C}$ and $4{ }^{\circ} \mathrm{C}$. Spores were not detected for three weeks at $4{ }^{\circ} \mathrm{C}$ in cheese slurry made with $1.3 \%$ salt, or during week 2 with $2 \%$ salt. Gas production was observed after one week at $30{ }^{\circ} \mathrm{C}$ only in the control slurry made with $1.3 \%$ salt. In slurry made with the protective strain, the reduction in C. tyrobutyricum count was $0.6 \log _{10}$ in the second week at $4{ }^{\circ} \mathrm{C}$ with both salt concentration. At $4{ }^{\circ} \mathrm{C}$, nisin production started in week 2 and reached $97 \mu \mathrm{g} / \mathrm{g}$ after four weeks. Metabarcoding analysis targeting the sequencing of $16 \mathrm{~S}$ rRNA revealed that the genus Lactococcus dominated for four weeks at $4{ }^{\circ} \mathrm{C}$. In cheese slurry made with $2 \%$ salt, the relative abundance of the genus Clostridium decreased significantly in the presence of nisin or the protective strain. The results indicated that both strategies are able to control the growth of Clostridium development in Cheddar cheese slurries.
\end{abstract}

Keywords: Nisin; protective starter; antimicrobial peptides; Cheddar cheese slurry; Clostridium tyrobutyricum; Lactococcus lactis; dairy products

\section{Introduction}

Clostridium (C.) tyrobutyricum is a Gram-positive, obligately anaerobic endosporeforming bacterium. In semi-hard and hard cheeses, it is capable of metabolizing lactic acid and producing butyric acid, hydrogen and carbon dioxide, which leads to major defects such as late blowing, swelling and splitting of blocks, brittle texture and foul odor [1,2]. Since the cost of bringing cheese to this stage of ripening is considerable, these defects cause significant economic losses [3,4]. Different approaches have been used to eliminate $C$. tyrobutricum from value-added food products, especially cheese. These include physical methods like bactofugation or microfiltration of milk. Such methods remain expensive in addition to causing significant modification of milk composition. Moreover, microfiltration should be applied to skim milk since fat globules clog filters [5,6]. Antimicrobial substances such as nitrate, lysozyme or salt have been used to prevent growth of $C$. tyrobutyricum $[7,8]$. The problem with nitrate is its conversion to nitrite by milk bacteria that express xanthine oxidase [9], possibly leading to the formation of nitrosamine, a carcinogen [7]. Also, such methods are not permitted for the Protected Designation of Origin (PDO) products [10]. The problem with lysozyme is that it comes from hen's egg, 
to which some individuals are allergic [11]. Salt is effective at concentrations of $0.5-2.5 \%$ in soft, hard and semi hard cheeses and 3.5-5\% in blue cheese [12]. However, salty foods have fallen into disfavor because their consumption increases the risk of hypertension, cardiovascular disease and kidney failure [13]. Salt is an important ingredient in Cheddar cheese, playing a major role in the development of flavor, texture and microbiological stability [14]. Reducing salt concentration has become a major challenge to producers of processed foods in general, including cheese [12]. Therefore, new ways of inhibiting C. tyrobutyricum in cheese are needed.

Promising alternative food preservatives are protective bacterial cultures or concentrated active metabolites from lactic acid bacteria (LAB). They are known to produce a wide variety of antimicrobial substances, such as bacteriocins $[15,16]$. Bacteriocins are antimicrobial peptides or proteins, sometimes of complex structure, synthesized by ribosomes and secreted with or without post-translational modification [17].

Although many bacteriocins have been discovered, nisin remains the only one approved as a food additive by the European Food Safety Authority (EFSA) and Food and Drug Administration (FDA) and has number E234 [18]. Consisting of 34 amino acid residues, nisin is mainly produced by Lactococcus lactis strains. Many types are known, which differ in some amino acids like nisin A, Z, F and U [19]. Nisin has an antimicrobial effect against a wide range of Gram-positive foodborne and spoilage bacteria [20,21].

Nisin was discovered in 1928, but its efficacy in food matrices is based on limited study [19]. Food-grade nisin is difficult to produce on a large scale. The peptide seems to be unstable in food matrices, especially in foods fermented with LAB, which are known to produce many proteases. Its hydrophobicity causes it to bind strongly to certain food constituents which decrease its effectiveness during product storage. For these reasons, the use of nisin as a food additive has been scant [22,23]. The aim of the present study was to evaluate the effectiveness of a nisin-producing Lactococcus lactis strain as an inhibitor of the growth and development of $C$. tyrobutyricum in Cheddar cheese and to compare it with encapsulated nisin.

\section{Materials and Methods}

\subsection{Bacterial Cultures}

Lactococcus lactis ssp. lactis CUC-H and Lactococcus lactis ssp. cremoris CUC 222 were obtained from Agriculture and Agri-Food Canada, St-Hyacinthe Research and Development Center (used as a starter). The nisin-A producing Lactococcus lactis ssp. lactis 32 strain (the only nisin-A producing strain) was obtained from Laval university culture collection. All LAB strains were activated for $16 \mathrm{~h}$ in De Man, Rogosa and Sharpe (MRS), Nutri Bact, Canada, broth medium at $37^{\circ} \mathrm{C}$ and transferred once before use. The Clostridium tyrobutyricum ATCC 25755 was activated in Reinforced Clostridial Medium (RCM), Nutri Bact, Canada, under anaerobic conditions at $37^{\circ} \mathrm{C}$ and transferred once [24].

\subsection{Spore Production}

Spores were prepared according to a published method [25] with the following modifications: RCM broth was inoculated with culture $(1 \% v / v)$ and incubated for two weeks at $37^{\circ} \mathrm{C}$ in an anaerobic chamber (Forma Scientific, Inc., Ohio, OH, USA). The spores were collected by centrifugation at $5000 \times g$ at $4{ }^{\circ} \mathrm{C}$ for $10 \mathrm{~min}$ and resuspended in sterilized reconstituted skim milk, Nutri Bact, Canada, $(12 \% w / v)$. The spore suspension was heated at $85^{\circ} \mathrm{C}$ for $5 \mathrm{~min}$ to kill the vegitative cells. Spores were enumerated using RCM agar and incubated under anarobic condition at $37^{\circ} \mathrm{C}$ [24].

\subsection{Pearce Test}

To select the best ratio between Lactococcus strains the Pearce test was done. The Lactococcus strains were grown in MRS medium for $16 \mathrm{~h}$ at $30^{\circ} \mathrm{C}$. Cultures were centrifuged at $5000 \times g$ for $5 \mathrm{~min}$ and the pellets were washed twice with $0.85 \%$ saline solution. All strains were standardized to an optical density of 0.2 at $600 \mathrm{~nm}$ using $0.15 \%$ peptone water, 
Nutri Bact, Canada. Sterilized reconstituted skim milk $(40 \mathrm{~mL}, 12 \% w / v)$ was inoculated with standardized strains suspension at different ratios and incubated on a Cheddar cheese temperature cycle [26,27]. Samples were taken aseptically at $0 \mathrm{~h}, 2 \mathrm{~h}$ and $5 \mathrm{~h}$ for the determination of $\mathrm{pH}$, bacterial count and bacteriocin production.

\subsection{Nisin Encapsulation}

Nisin in a commercial form (Nisaplin ${ }^{\circledR}, 2.5 \%$ nisin, Cayman Chemicals, Ann Arbor, MI, USA) was purified on a Sep-Pack C 18 column at $4{ }^{\circ} \mathrm{C}$ at a flow rate of $3 \mathrm{~mL} / \mathrm{min}$ and concentrated with Speed-Vac for $6 \mathrm{~h}$ at $50{ }^{\circ} \mathrm{C}$ Its concentration was measured by Highperformance liquid chromatography (HPLC) [24]. It was then microencapsulated in 1\% sodium alginate (Sigma Aldrich, Oakville, ON, Canada) with $0.5 \%$ non-gelatinized resistant starch (Manitoba Starch products Inc, Carberry, MB, Canada) as described previously [26] using an Inotech IE-20 encapsulator (Inotech Biosystems International, Inc., Rockville, MD, USA) with a $300 \mu \mathrm{m}$ nozzle and syringe pump set at a flow rate of $2.91 \mathrm{~mL} / \mathrm{min}$ to form droplets stabilized on contact with sterile $5 \%$ calcium chloride solution at $\mathrm{pH} 6.00$. The encapsulator vibration frequency was set at $2000 \mathrm{~Hz}$. The resulting beads were stirred at $300 \mathrm{rpm}$ for $4 \mathrm{~h}$ at room temperature. The encapsulation efficiency was determined as described previously. Microcapsules were added to milk to obtain a nisin concentration of $50 \mu \mathrm{g} / \mathrm{mL}[24]$.

\subsection{Cheese Slurry Preparation and Experimental Treatments}

The cheese slurry was prepared as described previously [26]. Pasteurized milk was acidified with glucono- $\delta$-lactone (Sigma, St-Louis, MO, USA). The unsalted fresh curd was lyophilized, then reduced to powder in a Quadro ComIL disc grinder (Waterloo, ON, Canada) and irradiated at $5 \mathrm{kGy}$ with Cobalt 60 for $2 \mathrm{~h}$. The $\mathrm{pH}$ was adjusted with concentrated lactic acid. The experimental formulations are shown in Table 1.

Table 1. The composition of different Cheddar cheese slurry groups.

\begin{tabular}{|c|c|c|c|c|}
\hline \multirow{2}{*}{ Ingredient (g) } & \multicolumn{2}{|c|}{ pH 5.3} & \multicolumn{2}{|c|}{ pH 5.00} \\
\hline & $1 \% \mathrm{NaCl}$ & $2 \% \mathrm{NaCl}$ & $1 \% \mathrm{NaCl}$ & $2 \% \mathrm{NaCl}$ \\
\hline Cheese powder & 180 & 180 & 180 & 180 \\
\hline $\mathrm{NaCl}$ solutions $\mathrm{pH} 2.0$ & $\begin{array}{c}102.9 \\
(\mathrm{NaCl} 3.2 \%)\end{array}$ & $\begin{array}{c}102.9 \\
(\mathrm{NaCl} 3.8 \%)\end{array}$ & $\begin{array}{c}102.9 \\
(\mathrm{NaCl} 3.2 \%)\end{array}$ & $\begin{array}{c}102.9 \\
(\mathrm{NaCl} 3.8 \%)\end{array}$ \\
\hline Starter culture & 6 & 6 & 6 & 6 \\
\hline Clostridium tyrobutyricum & 6 & 6 & 6 & 6 \\
\hline Phosphate buffer & 5.1 or $0.6^{\mathrm{a}, \mathrm{b}}$ & 5.1 or $0.6^{a, b}$ & 5.1 or $0.6^{a, b}$ & 5.1 or $0.6^{a, b}$ \\
\hline Nisin capsules $(\mathrm{EN})^{\mathrm{a}}$ & 4.5 & 4.5 & 4.5 & 4.5 \\
\hline Protective strain $b$ & 4.5 & 4.5 & 4.5 & 4.5 \\
\hline Total weight & 300 & 300 & 300 & 300 \\
\hline Target moisture content & $38 \%$ & $38 \%$ & $38 \%$ & $38 \%$ \\
\hline
\end{tabular}

${ }^{\mathrm{a}}$ encapsulated nisin group, and ${ }^{\mathrm{b}}$ protective strain group.

Each slurry was divided into three groups of $100 \mathrm{~g}$ as follows:

Group 1: Cheddar cheese starter $\left(8 \log _{10} \mathrm{cfu} / \mathrm{g}\right)+$ C. tyrobutyricum $\left(4 \log _{10} \mathrm{cfu} / \mathrm{g}\right)$

Group 2: Cheddar cheese starter $\left(8 \log _{10} \mathrm{cfu} / \mathrm{g}\right)+$ C. tyrobutyricum $\left(4 \log _{10} \mathrm{cfu} / \mathrm{g}\right)+$ encapsulated nisin

Group 3: Cheddar cheese starter $\left(8 \log _{10} \mathrm{cfu} / \mathrm{g}\right)+$ C. tyrobutyricum $\left(4 \log _{10} \mathrm{cfu} / \mathrm{g}\right)+$ L. lactis ssp. lactis 32 (nisin A producer)

The slurry was incubated for four weeks at $4{ }^{\circ} \mathrm{C}$ or for two weeks at $30^{\circ} \mathrm{C}$ to accelerate the reactions to mimic the condition after one year. Chemical composition, bacterial counts and free nisin concentration were measured weekly. Weighed samples (about $2.5 \mathrm{~g}$ ) were 
blended with $22.5 \mathrm{~mL}$ of peptone water in a stomacher (Seward model 400, Norfolk, UK) and diluted serially. For $C$. tyrobutyricum counts, a portion of each dilution was heated to $85^{\circ} \mathrm{C}$ for $10 \mathrm{~min}$ before plating $(1 \mathrm{~mL})$ using $\mathrm{RCM}$ medium at $37^{\circ} \mathrm{C}$ under anaerobic condition. All cheese analyses were carried out in triplicate. Fat and moisture contents were measured using the CEM (SMART 6 Moisture/Solids Analyzer).

\subsection{Nisin Determination by HPLC}

Nisin extraction from cheese was performed as described in Jarvis, (2016) with some modifications. Two grams of cheese slurry were added to $8 \mathrm{~mL}$ of $0.02 \mathrm{~N} \mathrm{HCl}$ then homogenized for $1 \mathrm{~min}$ at high speed before the slurry was boiled at $98{ }^{\circ} \mathrm{C}$ for $5 \mathrm{~min}$. The extract was cooled immediately to $20{ }^{\circ} \mathrm{C}$ followed by centrifugation at $10,000 \times g, 4{ }^{\circ} \mathrm{C}$ for $30 \mathrm{~min}$. The fat layer was removed, and the supernatant was filtered through a $0.2 \mu \mathrm{m}$ filter before being analyzed by a reverse-phase HPLC (HPLC Hewlett Packard Series 1100; Agilent technologies Canada Inc., Saint-Laurent, QC, Canada) [24].

\subsection{Metagenomic Analysis}

\subsubsection{Sample Preparation}

One $\mathrm{mL}$ of the cheese suspension was centrifuged at $10,000 \times \mathrm{g}$ for $20 \mathrm{~min}$, and the fat layer was removed before the cell pellet was suspended in $500 \mathrm{~mL}$ of a TE $2 X$ solution (20 mM Tris $\mathrm{HCl}$ pH 8.0, 2 mM EDTA). 1.25 $\mu \mathrm{L}$ of Propidium monoazide (PMA) solution (Biotium Inc., Hayward, CA, USA) was added to bacterial suspension. The tubes were shaken in the dark for 5 min to allow for maximal PMA contact with DNA, then all tubes were exposed to a PMA lamp apparatus under ice (halogen 500W, Ingenia Biosystems, Barcelona, Spain) for $15 \mathrm{~min}$. Finally, all tubes were recentrifuged at $10,000 \times g$ for $15 \mathrm{~min}$ to recover cell pellets for DNA extraction and stored at $-20{ }^{\circ} \mathrm{C}$ [28] as described below.

\subsubsection{DNA Extraction from Cheese Samples}

Total DNA was extracted from cheese samples according to Desfossés-Foucault et al. (2012) using Tissue Kit of Gram-positive bacteria (Qiagen, Mississauga, ON, Canada). all DNA samples were kept at $-20{ }^{\circ} \mathrm{C}$ until analysis [26].

\subsubsection{S rRNA Sequencing and Analysis}

The diversity of the cheese microbiome was assessed by sequencing the bacterial $16 \mathrm{~S}$ rRNA gene in the V3-V4 region using the amplification primers 341F (5' CCTACGGGNGG CWGCAG-3') and 805R (5'-GACTACHVGGGTATCTAATCC-3') adapted to incorporate the transposon-based Illumina Nextera adapters (Illumina, San Diego, CA, USA) and a sample barcode sequence allowing multiplexed sequencing. High-throughput sequencing was performed at the Institute for Integrative Systems Biology at Université Laval, QC, Canada on a MiSeq platform using $2 \times 300$ bp paired-end sequencing (Illumina, San Diego, CA, USA). The 16S rRNA gene was profiled using demultiplexed raw data processed with Mothur software (v1.35.1) as described previously [27]. Sequences were aligned using the bacterial reference database SILVA with the align.seqs command. The sequences were clustered into operational taxonomic units (OTUs) using the OPTI parameter. Representative OTU sequences were assigned to taxa based on the Green genes reference database [28].

\subsection{Statistical Analysis}

A split-plot design was applied to determine the effect of time on bacterial growth and the effect of $\mathrm{NaCl}$ concentration, $\mathrm{pH}$ and time on Clostridium and starter strain counts. All experiments were performed three times. Effects were declared significant at $p \leq 0.05$. Statistical analyses were carried out using the SAS general linear models' procedure (version 9.1.3, Cary, NC, USA). 


\section{Results}

\subsection{Selection of Mixed Culture Ratio and Production of Encapsulated Nisin}

All three Lactococcus lactis strains grew well in skim milk under Cheddar cheese temperature cycle conditions. Growth, final $\mathrm{pH}$ and bacteriocin production varied between strains (Tables 2-4). Strain L. lactis ssp. lactis CUC-H was the strongest acidifier after $5 \mathrm{~h}$ of incubation. Production of nisin-A by L. lactis ssp. lactis 32 started after $5 \mathrm{~h}$. The most compatible combination was L. lactis spp. lactis CUC-H, L. lactis spp. cremoris 222 and L. lactis spp. lactis 32 at a ratio of 1:1:1.5 for a total inoculum volume of $2 \%$. This provides optimal growth and maximal acid production.

Table 2. Acidification of skim milk by different strains of Lactococcus lactis in pure culture or in combination under the Cheddar cheese temperature cycle.

\begin{tabular}{|c|c|c|c|}
\hline & \multicolumn{3}{|c|}{$\mathrm{pH}$} \\
\hline & Time Zero & $2 \mathrm{~h}$ & $5 \mathrm{~h}$ \\
\hline Lactococcus lactis ssp. lactis 32 & $6.54 \mathrm{~d}$ & $6.51 \mathrm{~b}$ & $5.76 \mathrm{~b}$ \\
\hline Lactococcus lactis ssp. cremoris CUC 222 & $6.55 \mathrm{c}$ & $6.51 \mathrm{~b}$ & $5.83 \mathrm{a}$ \\
\hline Lactococcus lactis ssp. lactis CUC-H & $6.57 \mathrm{a}$ & $6.52 \mathrm{a}$ & $5.53 \mathrm{~g}$ \\
\hline Lactococcus lactis ssp. lactis $32+$ Lactococcus lactis ssp. cremoris CUC222 (1:1) & $6.57 \mathrm{a}$ & $6.51 \mathrm{~b}$ & $5.67 \mathrm{c}$ \\
\hline Lactococcus lactis ssp. lactis $32+$ Lactococcus lactis ssp. lactis CUC-H (1:1) & $6.56 \mathrm{~b}$ & $6.5 \mathrm{c}$ & $5.48 \mathrm{~h}$ \\
\hline $\begin{array}{l}\text { Lactococcus lactis ssp. cremoris CUC222 + Lactococcus lactis ssp. lactis } \\
\text { CUC-H (1:1) }\end{array}$ & $6.55 \mathrm{c}$ & $6.5 \mathrm{c}$ & $5.48 \mathrm{~h}$ \\
\hline $\begin{array}{l}\text { Lactococcus lactis ssp. lactis } 32+\text { Lactococcus lactis ssp. cremoris CUC222 + } \\
\text { Lactococcus lactis ssp. lactis CUC-H (1:1:1) }\end{array}$ & $6.55 c$ & $6.5 \mathrm{c}$ & $5.56 \mathrm{e}$ \\
\hline $\begin{array}{l}\text { Lactococcus lactis ssp. lactis } 32+\text { Lactococcus lactis ssp. cremoris CUC222 + } \\
\text { Lactococcus lactis ssp. lactis CUC-H (1.5:1:1) }\end{array}$ & $6.55 c$ & $6.49 \mathrm{~d}$ & $5.55 \mathrm{f}$ \\
\hline $\begin{array}{l}\text { Lactococcus lactis ssp. lactis } 32+\text { Lactococcus lactis ssp. cremoris CUC222 + } \\
\text { Lactococcus lactis ssp. lactis CUC-H (1.5:1:1) } \%\end{array}$ & $6.55 c$ & $6.44 \mathrm{f}$ & $5.23 \mathrm{i}$ \\
\hline $\begin{array}{l}\text { Lactococcus lactis ssp. lactis } 32+\text { Lactococcus lactis ssp. cremoris CUC222 + } \\
\text { Lactococcus lactis ssp. lactis CUC-H (2:1:1) }\end{array}$ & $6.55 c$ & $6.48 \mathrm{e}$ & $5.56 \mathrm{e}$ \\
\hline
\end{tabular}

Different letters indicate significant difference $(p<0.05)$.

Table 3. Viable counts of Lactococcus lactis in skim milk in pure culture or in combination under the Cheddar cheese temperature cycle $(n=3)$.

\begin{tabular}{lccc}
\hline & \multicolumn{2}{c}{ Viable Count Log10 cfu/mL } \\
\cline { 2 - 3 } & Time Zero & $\mathbf{2 ~ h}$ & $\mathbf{5 ~ h}$ \\
\hline Lactococcus lactis ssp. lactis 32 & $6.10 \pm 0.01 \mathrm{~d}$ & $7.46 \pm 0.02 \mathrm{c}$ & $8.69 \pm \mathrm{e}$ \\
\hline Lactococcus lactis ssp. cremoris CUC 222 & $5.40 \pm 0.02 \mathrm{~h}$ & $5.70 \pm 0.03 \mathrm{f}$ & $7.63 \pm 0.02 \mathrm{~g}$ \\
\hline Lactococcus lactis ssp. lactis CUC-H & $6.44 \pm 0.02 \mathrm{~b}$ & $7.40 \pm 0.01 \mathrm{~d}$ & $8.92 \pm 0.02 \mathrm{a}$ \\
\hline Lactococcus lactis ssp. lactis 32 + Lactococcus lactis ssp. cremoris CUC222 (1:1) & $6.00 \pm 0.03 \mathrm{e}$ & $7.40 \pm 0.02 \mathrm{~d}$ & $8.60 \pm 0.02 \mathrm{f}$ \\
\hline Lactococcus lactis ssp. lactis 32+Lactococcus lactis ssp. lactis CUC-H $(1: 1)$ & $6.26 \pm 0.01 \mathrm{c}$ & $7.49 \pm 0.01 \mathrm{~b}, \mathrm{c}$ & $8.86 \pm \mathrm{b}$ \\
\hline $\begin{array}{l}\text { Lactococcus lactis ssp. cremoris CUC222 + Lactococcus lactis ssp. lactis } \\
\text { CUC-H (1:1) }\end{array}$ & $5.85 \pm 0.02 \mathrm{f}$ & $7.21 \pm 0.03 \mathrm{e}$ & $8.79 \pm 0.01 \mathrm{~d}$ \\
\hline $\begin{array}{l}\text { Lactococcus lactis ssp. lactis 32 + Lactococcus lactis ssp. cremoris CUC222 }+ \\
\text { Lactococcus lactis ssp. lactis CUC-H (1:1:1) }\end{array}$ & $5.70 \pm 0.03 \mathrm{~g}$ & $7.51 \pm 0.03 \mathrm{~b}$ & $8.78 \pm 0.01 \mathrm{~d}$ \\
\hline
\end{tabular}


Table 3. Cont.

\begin{tabular}{|c|c|c|c|}
\hline & \multicolumn{3}{|c|}{ Viable Count Log10 cfu/mL } \\
\hline & Time Zero & $2 \mathrm{~h}$ & $5 \mathrm{~h}$ \\
\hline $\begin{array}{l}\text { Lactococcus lactis ssp. lactis } 32+\text { Lactococcus lactis ssp. cremoris CUC222 + } \\
\text { Lactococcus lactis ssp. lactis CUC-H (1.5:1:1) }\end{array}$ & $6.01 \pm 0.01 \mathrm{e}$ & $7.41 \pm 0.01 \mathrm{~d}$ & $8.83 \pm 0.01 \mathrm{c}$ \\
\hline $\begin{array}{l}\text { Lactococcus lactis ssp. lactis } 32+\text { Lactococcus lactis ssp. cremoris CUC222 + } \\
\text { Lactococcus lactis ssp. lactis CUC-H (1.5:1:1) } 2 \%\end{array}$ & $6.24 \pm 0.04 \mathrm{c}$ & $7.81 \pm 0.0 \mathrm{a}$ & $8.87 \pm 0.01 b$ \\
\hline $\begin{array}{l}\text { Lactococcus lactis ssp. lactis } 32+\text { Lactococcus lactis ssp. cremoris CUC222 + } \\
\text { Lactococcus lactis ssp. lactis CUC-H (2:1:1) }\end{array}$ & $6.60 \pm 0.01 \mathrm{a}$ & $7.46 \pm 0.01 c$ & $8.80 \pm 0.01 \mathrm{~d}$ \\
\hline
\end{tabular}

Different letters indicate significant difference $(p<0.05)$.

Table 4. Nisin-A production by the nisin-producing strain of Lactococcus lactis in skim milk; pure culture or combination under the Cheddar cheese temperature cycle $(n=3)$.

\begin{tabular}{|c|c|c|c|}
\hline & \multicolumn{3}{|c|}{ Nisin-A (AU/mL) } \\
\hline & Time Zero & $2 \mathrm{~h}$ & $5 \mathrm{~h}$ \\
\hline L. lactis 32 & ND & ND & 64 \\
\hline Lactococcus lactis ssp. lactis 32 + Lactococcus lactis ssp. cremoris CUC222 (1:1) & ND & ND & 64 \\
\hline Lactococcus lactis ssp. lactis $32+$ Lactococcus lactis ssp. lactis CUC-H (1:1) & ND & ND & 64 \\
\hline $\begin{array}{l}\text { Lactococcus lactis ssp. lactis } 32+\text { Lactococcus lactis ssp. cremoris CUC222 + } \\
\text { Lactococcus lactis ssp. lactis CUC-H (1:1:1) }\end{array}$ & ND & ND & 64 \\
\hline $\begin{array}{l}\text { Lactococcus lactis ssp. lactis } 32+\text { Lactococcus lactis ssp. cremoris CUC222 + } \\
\text { Lactococcus lactis ssp. lactis CUC-H (1.5:1:1) }\end{array}$ & ND & ND & 64 \\
\hline $\begin{array}{l}\text { Lactococcus lactis ssp. lactis } 32+\text { Lactococcus lactis ssp. cremoris CUC222 + } \\
\text { Lactococcus lactis ssp. lactis CUC-H }(1.5: 1: 1) 2 \%\end{array}$ & ND & ND & 256 \\
\hline $\begin{array}{l}\text { Lactococcus lactis ssp. lactis } 32+\text { Lactococcus lactis ssp. cremoris CUC222 + } \\
\text { Lactococcus lactis ssp. lactis CUC-H (2:1:1) }\end{array}$ & ND & ND & 64 \\
\hline
\end{tabular}

ND: none detected, AU: Arbitrary unit.

\subsection{Chemical and Microbiological Composition of Cheese Slurry}

The slurries had similar chemical compositions, which corresponded to the normal composition of Cheddar cheese (Table 5), except for the $\mathrm{NaCl}$ concentration. At $2.0 \%$ $\mathrm{NaCl}$, no significant difference was found between $\mathrm{pH} 5.0$ and 5.3 on Lactococcus counts. Therefore, only the data of $\mathrm{pH} 5.3$ will be presented. At $2 \%$ salt concentration, a slight reduction was seen in the control group at $4{ }^{\circ} \mathrm{C}$ after four weeks. On the other hand, the presence of encapsulated nisin was associated with an approximately $1 \log _{10}$ reduction until the second week. The total bacterial counts increased again during the third week $(p \leq 0.05)$, likely due to the gradual release of nisin from capsules. In the presence of the nisin-A producer (strain 32), counts appeared stable over time. At $1.3 \% \mathrm{NaCl}$, the same trend overall was observed (Figure 1).

At $30{ }^{\circ} \mathrm{C}$, the total bacterial counts in control fell by about $0.3 \log _{10}$, a $1.0 \log _{10}$ reduction $(p \leq 0.05)$ was noted in the encapsulated nisin-A group at $2 \%$ salt, while it was $0.6 \log _{10}$ at $1.3 \%$ salt, and a slight reduction appeared in the presence of the protective strain, perhaps due to better bacterial growth at this temperature (Figure 2) at $2 \%$ salt. The gradual in situ production of nisin during storage was confirmed by quantitative HPLC. These results show that these $\mathrm{NaCl}$ concentrations and $\mathrm{pH}$ do not likely interfere with starter culture growth. 
Table 5. Chemical analysis of the cheese slurries at time zero.

\begin{tabular}{|c|c|c|c|c|}
\hline \multicolumn{5}{|c|}{ pH 5.0 and $1.3 \%$ salt } \\
\hline Groups & $\mathrm{NaCl} \%$ & Moisture \% & $\begin{array}{l}\text { Salt/Moisture } \\
\text { (S/M) }\end{array}$ & $\mathrm{pH}$ \\
\hline Control (+) & $1.36 \pm 0.01$ & $38.49 \pm 0.1$ & $3.52 \pm 0.03$ & $5.10 \pm 0.01$ \\
\hline Encapsulated nisin & $1.25 \pm 0.01$ & $38.53 \pm 0.1$ & $2.87 \pm 0.01$ & $5.12 \pm 0.01$ \\
\hline protective strain & $1.27 \pm 0.01$ & $38.42 \pm 0.2$ & $3.32 \pm 0.01$ & $5.00 \pm 0.01$ \\
\hline \multicolumn{5}{|c|}{$\mathrm{pH} 5.0$ and $2 \%$ salt } \\
\hline Groups & $\mathrm{NaCl} \%$ & Moisture \% & (S/M) & $\mathrm{pH}$ \\
\hline Control (+) & $2.01 \pm 0.01$ & $37.37 \pm 0.02$ & $5.38 \pm 0.01$ & $5.00 \pm 0.02$ \\
\hline Encapsulated nisin & $1.96 \pm 0.01$ & $38.26 \pm 0.03$ & $5.12 \pm 0.02$ & $5.10 \pm 0.01$ \\
\hline protective strain & $1.86 \pm 0.01$ & $37.65 \pm 0.02$ & $4.94 \pm 0.01$ & $5.00 \pm 0.01$ \\
\hline \multicolumn{5}{|c|}{ pH 5.3 and $1.3 \%$ salt } \\
\hline Groups & $\mathrm{NaCl} \%$ & Moisture \% & $(\mathrm{S} / \mathrm{M})$ & $\mathrm{pH}$ \\
\hline Control (+) & $1.34 \pm 0.01$ & $37.66 \pm 0.02$ & $3.56 \pm 0.01$ & $5.25 \pm 0.01$ \\
\hline Encapsulated nisin & $1.33 \pm 0.01$ & $39.03 \pm 0.01$ & $3.41 \pm 0.01$ & $5.24 \pm 0.01$ \\
\hline protective strain & $1.23 \pm 0.01$ & $38.30 \pm 0.02$ & $3.21 \pm 0.01$ & $5.24 \pm 0.01$ \\
\hline \multicolumn{5}{|c|}{$\mathrm{pH} 5.3$ and $2 \%$ salt } \\
\hline Groups & $\mathrm{NaCl} \%$ & Moisture \% & (S/M) & $\mathrm{pH}$ \\
\hline Control (+) & $1.88 \pm 0.02$ & $37.19 \pm 0.03$ & $5.05 \pm 0.03$ & $5.26 \pm 0.05$ \\
\hline Encapsulated nisin & $1.87 \pm 0.02$ & $37.37 \pm 0.02$ & $5.20 \pm 0.02$ & $5.28 \pm 0.01$ \\
\hline protective starter & $1.87 \pm 0.02$ & $37.38 \pm 0.01$ & $5.00 \pm 0.01$ & $5.28 \pm 0.01$ \\
\hline
\end{tabular}

(A) Salt 1.3\%

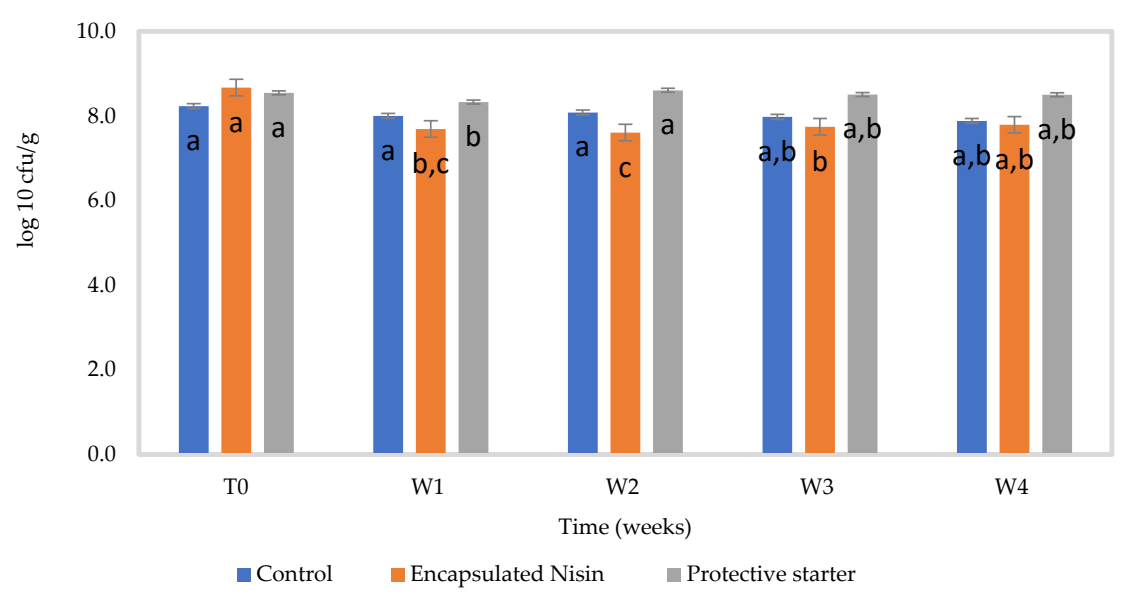

Figure 1. Cont. 
(B) Salt $2 \%$

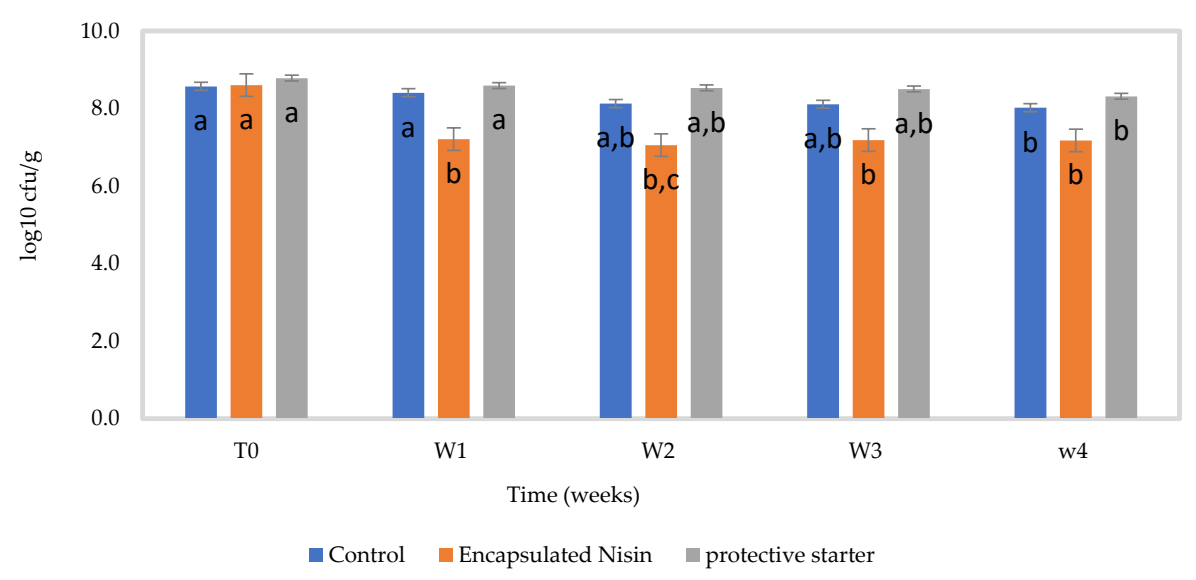

Figure 1. Total lactic acid bacteria count (starter culture) in Cheddar cheese slurries made with (A) $1.3 \% \mathrm{NaCl}$ and $(\mathbf{B}) 2 \% \mathrm{NaCl}$, stored for four weeks at $4{ }^{\circ} \mathrm{C}, \mathrm{pH} 5.3(n=3)$, different letters indicate significant difference $(p<0.05)$.

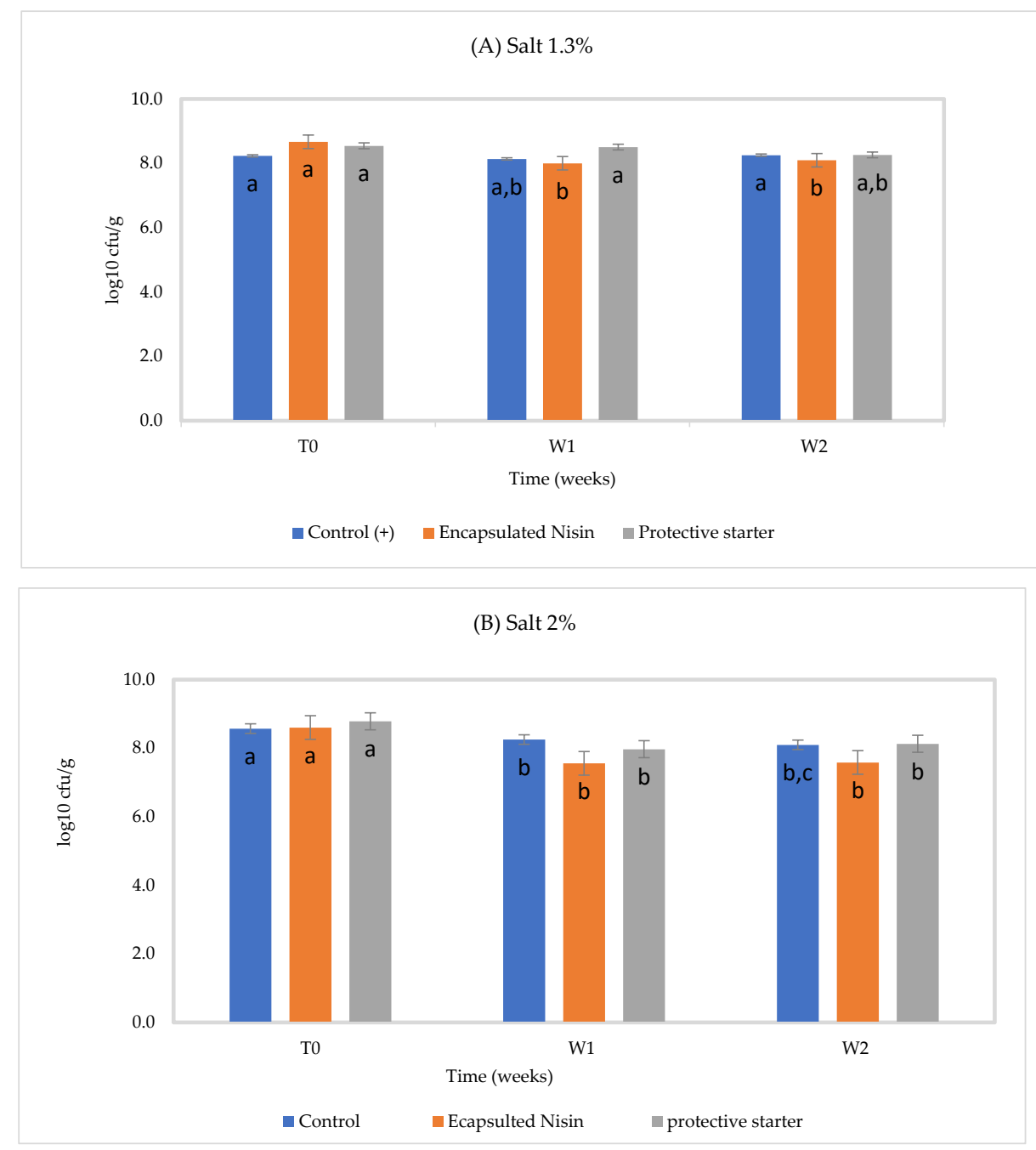

Figure 2. Total lactic acid bacteria count in Cheddar cheese slurries made with (A) $1.3 \% \mathrm{NaCl}$ and (B) $2 \% \mathrm{NaCl}$ stored for two weeks at $30{ }^{\circ} \mathrm{C},(n=3)$, Different letters indicate significant difference $(p<0.05)$. 
In the case of $C$. tyrobutyricum counts, significant reductions were noted after the first week in the presence of encapsulated nisin and in the second week in the protective strain treated group at $1.3 \%$ and $2 \% \mathrm{NaCl}$ at $4{ }^{\circ} \mathrm{C}$ (Figure 3). In the encapsulated nisintreated group, no spores were detected after the third week $(p \leq 0.05)$ in RCM medium. At $2 \% \mathrm{NaCl}$ under $4{ }^{\circ} \mathrm{C}$, none were detected after the second week, suggesting synergism between $\mathrm{NaCl}$ and nisin-A. We have also observed a $0.5 \log _{10}$ reduction in C. tyrobutyricum counts in the protective starter treated group compared to control $(p \leq 0.05)$ during four weeks of incubation under two salt concentrations at $4{ }^{\circ} \mathrm{C}$. This inhibition activity was associated with the gradual in situ production of nisin during storage, as confirmed by nisin quantification using HPLC. Gas production was observed in the control group at $1.3 \%$ $\mathrm{NaCl}$ at $30^{\circ} \mathrm{C}$ (Figure 4 ). The $\mathrm{C}$. tyrobutyricum count decreased by $0.74 \log$ after one week under both salt concentrations, while the count was maintained constantly at $30^{\circ} \mathrm{C}$ after first week (Table 6).
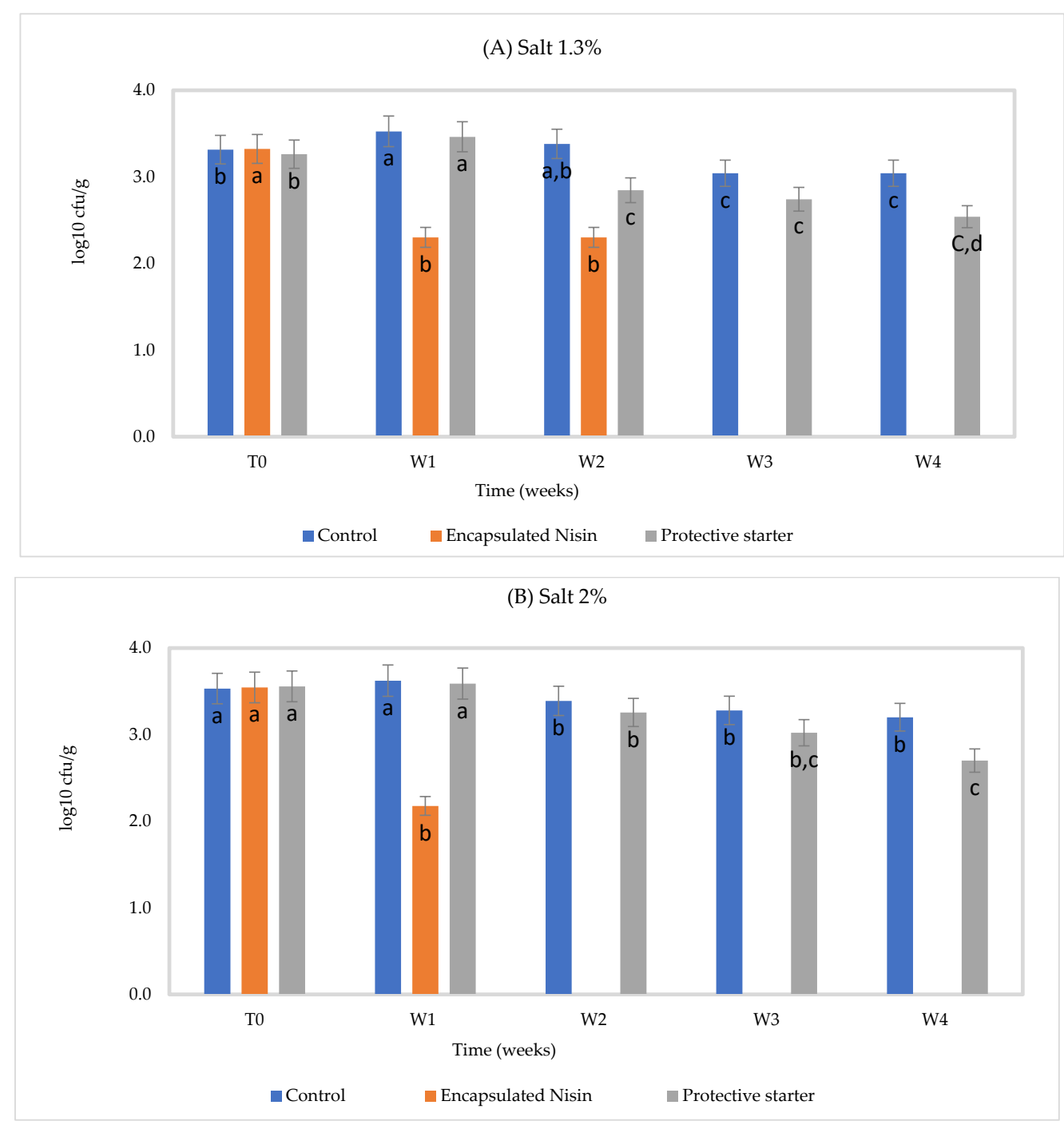

Figure 3. Clostridium tyrobutyricum count in Cheddar cheese slurries adjusted to $\mathrm{pH} 5.3$ and stored for four weeks at $4{ }^{\circ} \mathrm{C}$, (A) $1.3 \% \mathrm{NaCl}$ and (B) $2 \% \mathrm{NaCl}(n=3)$, Different letters indicate significant difference $(p<0.05)$. 


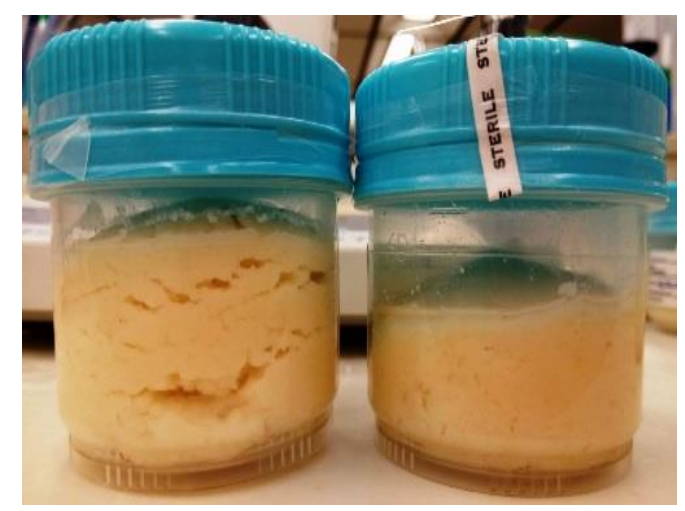

Figure 4. Gas swelling of Cheddar cheese slurry (made with $1.3 \% \mathrm{NaCl}$ ) by Clostridium tyrobutyricum after one week at $30^{\circ} \mathrm{C}$, left: control; right: containing encapsulated nisin-A.

Table 6. Clostridium tyrobutyricum counts in cheese slurry at $30^{\circ} \mathrm{C}(n=3)$.

\begin{tabular}{cccc}
\hline \multirow{2}{*}{ Treatment } & \multicolumn{3}{c}{ Log cfu/g at $2 \% \mathrm{NaCl}$} \\
\cline { 2 - 4 } & Time Zero & Week 1 & Week 2 \\
\hline Control & $3.53 \pm 0.02 \mathrm{~b}$ & $3.70 \pm 0.05 \mathrm{a}$ & $3.57 \pm 0.05 \mathrm{~b}$ \\
\hline Encapsulated nisin & $3.54 \pm 0.04 \mathrm{a}$ & $2.48 \pm 0.01 \mathrm{~b}$ & $2.30 \pm 0.02 \mathrm{c}$ \\
\hline protective starter & $3.56 \pm 0.02 \mathrm{a}$ & $3.51 \pm 0.05 \mathrm{a}$ & $3.10 \pm 0.01 \mathrm{~b}$ \\
\hline Treatment & & Log cfu/g at $1.3 \% \mathrm{NaCl}$ & \\
\cline { 2 - 4 } & Time Zero & Week 1 & Week 2 \\
\hline Control & $3.32 \pm 0.02 \mathrm{a}$ & $3.34 \pm 0.02 \mathrm{a}$ & Uncountable \\
& $3.32 \pm 0.02 \mathrm{~b}$ & $2.54 \pm 0.01 \mathrm{c}$ & $3.81 \pm 0.04 \mathrm{a}$ \\
\hline Encapsulated nisin & $3.26 \pm 0.03 \mathrm{~b}$ & $3.23 \pm 0.03 \mathrm{~b}$ & $3.80 \pm 0.04 \mathrm{a}$ \\
\hline protective starter & &
\end{tabular}

Different letters indicate significant difference $(p<0.05)$.

\subsection{In Situ Nisin Production}

Nisin production by L. lactis ssp lactis strain 32 (protective strain) in cheese slurry was not affected by $\mathrm{pH}$ (Figures 5-7). Production was gradual, reaching $97.54 \pm 1 \mu \mathrm{g} / \mathrm{g}$ at $2 \%$ $\mathrm{NaCl}$ and $80.92 \pm 1 \mu \mathrm{g} / \mathrm{g}$ at $1.3 \% \mathrm{NaCl}$ after four weeks at $4{ }^{\circ} \mathrm{C}$ (Figure 5). A higher salt concentration could increase nisin production by putting the bacterial cells under more stress [28]. Somewhat more nisin was found at $30^{\circ} \mathrm{C}$, which could be due to the suitable temperature for bacterial growth to produce bacteriocins (Figure 7). These results showed that L. lactis ssp lactis strain 32 was able to survive and produce nisin in cheese slurry during storage at both temperatures. We have also shown that encapsulation improves the stability of nisin and controls its release in cheese during storage. At $4{ }^{\circ} \mathrm{C}$ and in the presence of $2 \%$ salt, the concentration of released nisin increased gradually within 2 weeks then decreased to about $30 \mu \mathrm{g} / \mathrm{g}$ at $4{ }^{\circ} \mathrm{C}$ due to the reduction of nisin amount inside capsules. The rise and the fall were both slower with $1.3 \%$ salt (Figure 6). At $30^{\circ} \mathrm{C}$, the rise appears to have occurred within 1 week, followed by the same tendency to drop (Figure 8). 


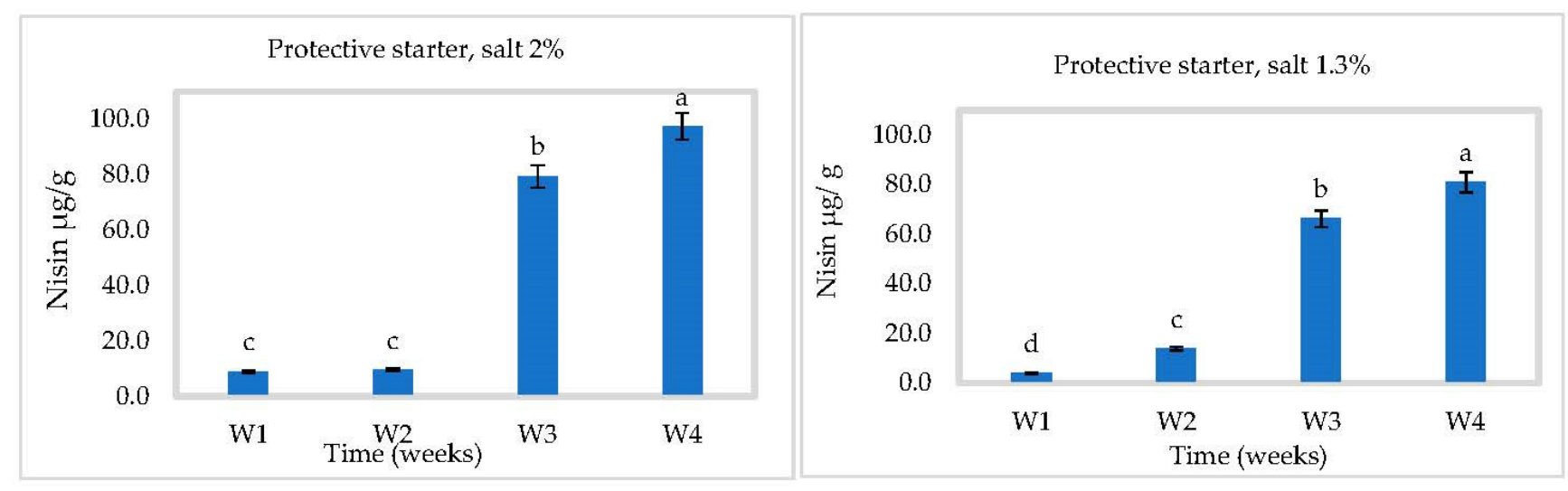

Figure 5. Nisin production in Cheddar cheese slurry containing bacteriocin-producing Lactococcus lactis ssp. lactis 32 (protective starter), during 4 weeks at $4{ }^{\circ} \mathrm{C}(n=3)$, Different letters indicate significant difference $(p<0.05)$.
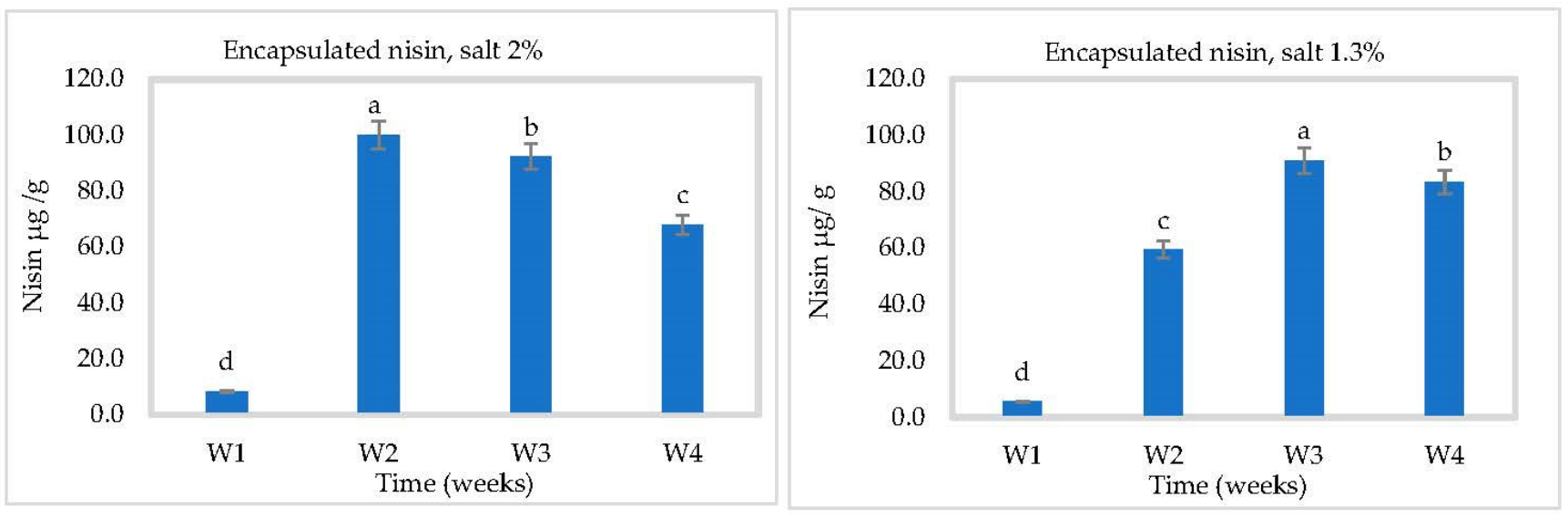

Figure 6. Nisin released in Cheddar cheese slurry containing the encapsulated bacteriocin, during 4 weeks at $4{ }^{\circ} \mathrm{C}(n=3)$, $\mathrm{W}=$ weeks, Different letters indicate significant difference $(p<0.05)$.

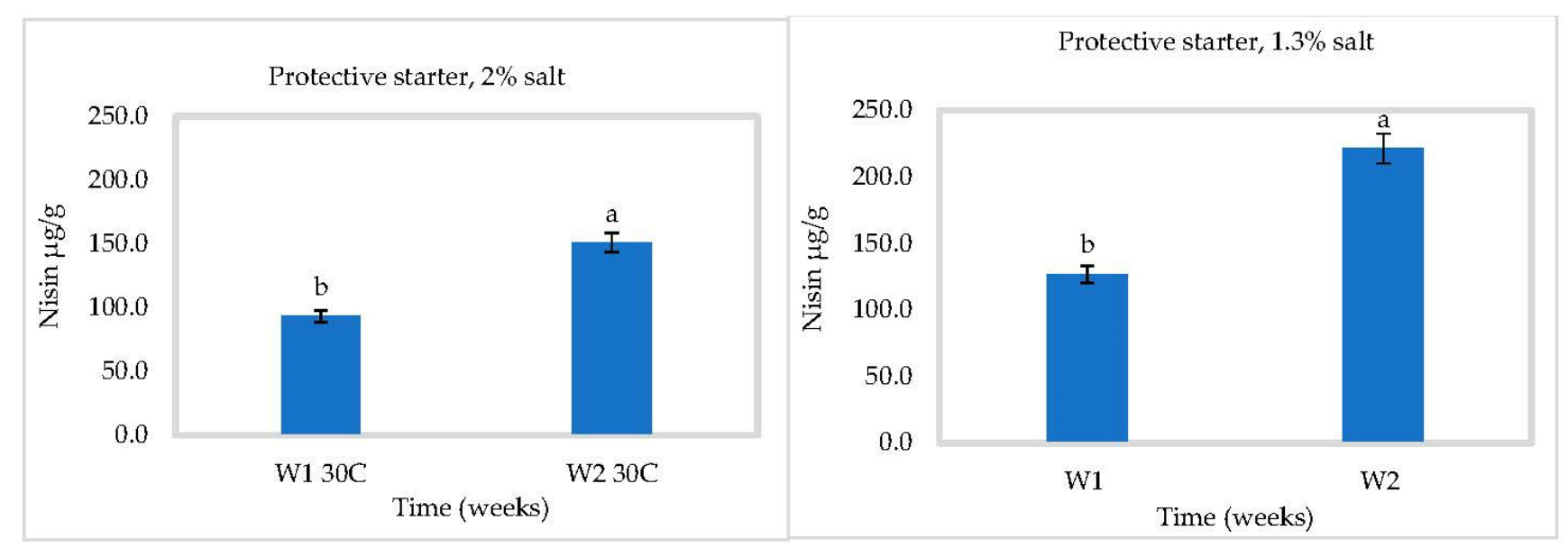

Figure 7. Nisin production in Cheddar cheese slurry containing bacteriocin-producing Lactococcus lactis ssp. lactis 32 (protective starter), during two weeks at $30^{\circ} \mathrm{C}(n=3)$, Different letters indicate significant difference $(p<0.05)$. 


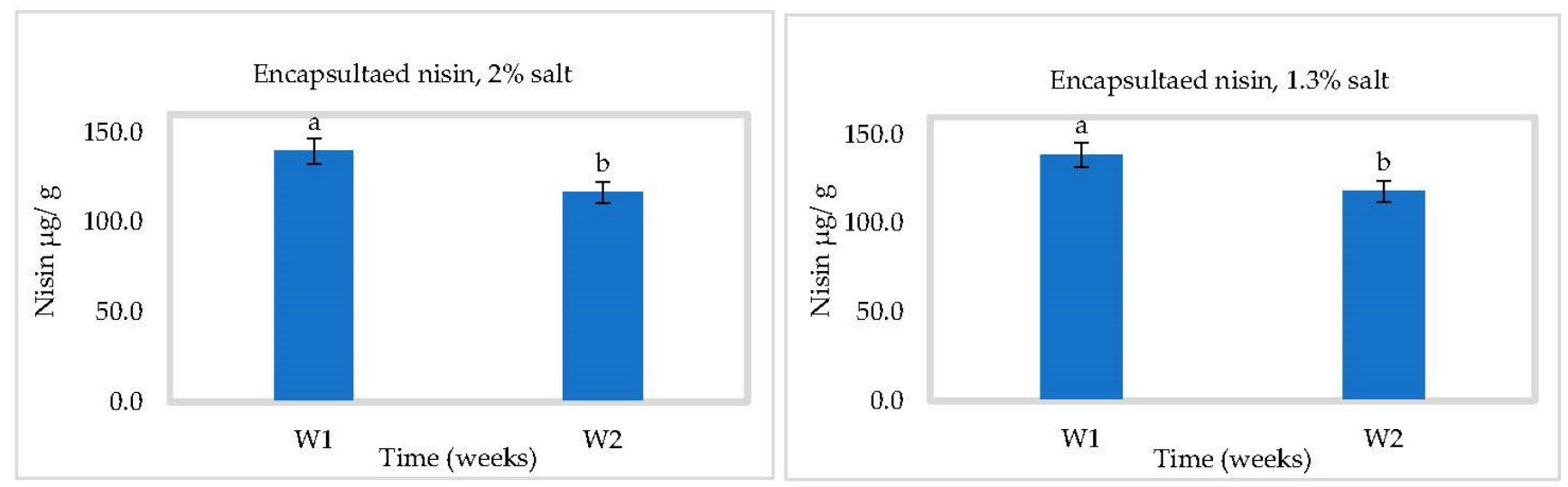

Figure 8. Nisin released in Cheddar cheese slurry containing the encapsulated bacteriocin, during two weeks at $30{ }^{\circ} \mathrm{C}$ $(n=3)$, Different letters indicate significant difference $(p<0.05)$.

\subsection{Metagenomics Analysis}

The impact of the nisin-A-producer strain and encapsulated nisin-A on the composition of Cheddar cheese slurry microbiota during storage was expressed in terms of the relative abundance of various families of bacteria. Figures 9 and 10 show the changes in the diversity of genera over time. In the protective strain treated group $(\mathrm{pH} 5.3$ at 1.3\% salt) incubated at $4{ }^{\circ} \mathrm{C}$, the genus Lactococcus was dominant at time zero, then increased significantly to $94 \%$ of the total bacteria after four weeks of incubation, followed by the encapsulated nisin treated group then the control group. The greatest drop in relative abundance of Clostridium at this temperature was observed in the encapsulated nisin treated group, followed by the bacteriocin-producing strain treated group compare to the control group.

After two weeks at $30{ }^{\circ} \mathrm{C}$ and $1.3 \% \mathrm{NaCl}$, the relative abundance of Clostridium spp. in the control group had increased significantly compared to the other groups. The proportion of genus Lactococcus had increased slightly and was still dominant, followed by the genus Pediococcus in the control and protective strain treated groups compared to the encapsulated nisin treated group. In this case, the genus Lactococcus decreased significantly with the increasing abundance of genus Pediococcus during the second week at $30{ }^{\circ} \mathrm{C}$ and $1.3 \% \mathrm{NaCl}$.

During four weeks at $4{ }^{\circ} \mathrm{C}$ and $2 \%$ salt, the relative abundance of Clostridium spp. increased in the slurry adjusted to $\mathrm{pH} 5.3$ and $2 \%$ salt. Meanwhile, Lactococcus declined significantly during week four at $2 \%$ salt in all groups, while the genus Pediococcus reached $85 \%, 64 \%$ and $55 \%$, respectively, in the control, encapsulated nisin and nisin producer strain treated groups. At $30{ }^{\circ} \mathrm{C}$ and $2 \%$ salt, in the control group the Clostridium abundance increased during the two weeks of incubation compare to the encapsulated nisin and the nisin producing strain treated groups $(p<0.05)$ due to the presence of nisin-A. 

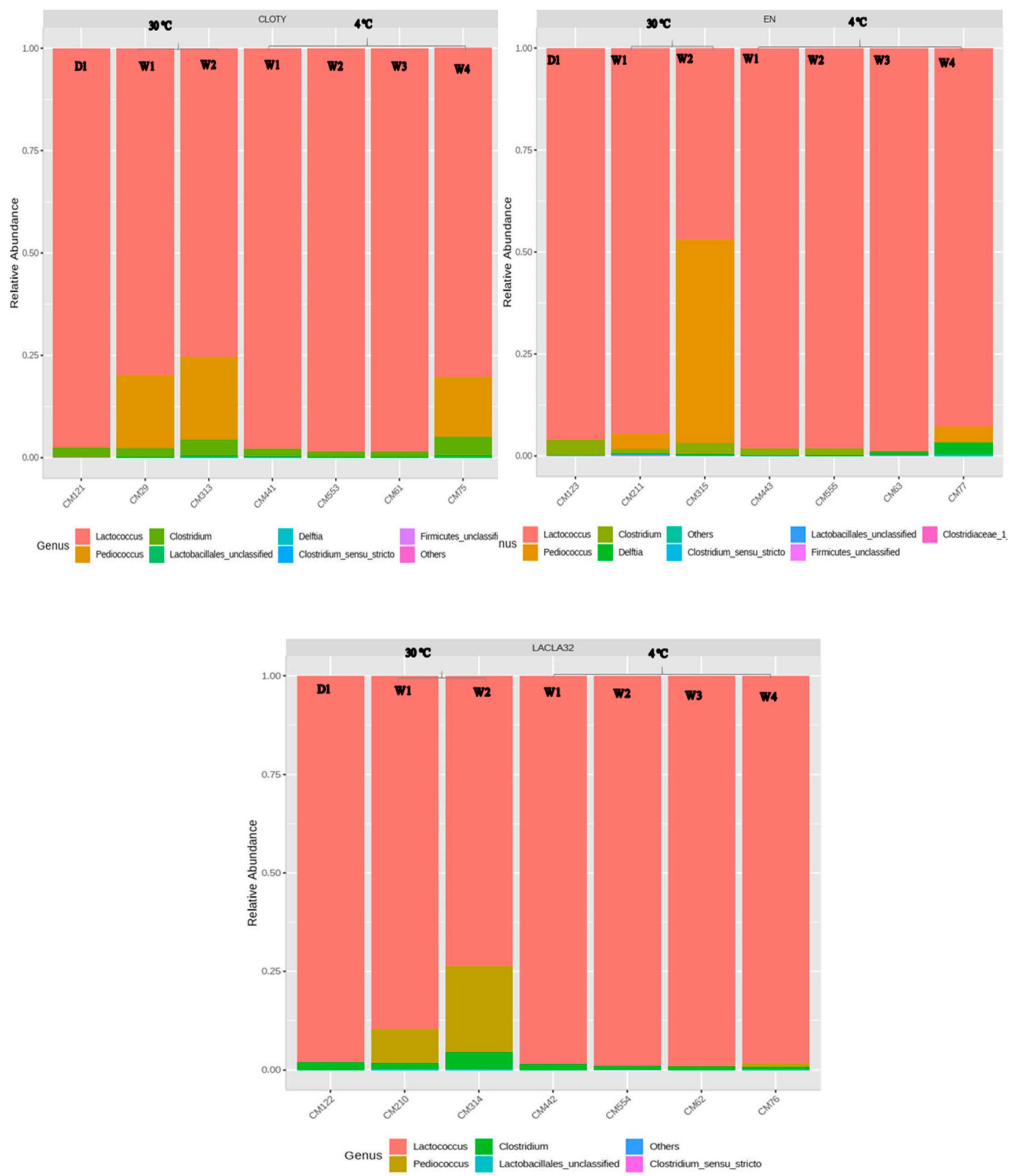

Figure 9. Relative abundance of bacterial genera, based on $16 \mathrm{~S}$ rRNA, in Cheddar cheese slurries containing C. tyrobutricum made with $1.3 \% \mathrm{NaCl}$. CLOTY) control, EN) Encapsulated nisin and LACLA32) protective strain treated group, stored for 4 weeks at $4{ }^{\circ} \mathrm{C}$ or for two weeks at $30^{\circ} \mathrm{C}(\mathrm{D} 1=$ time zero $)$. 

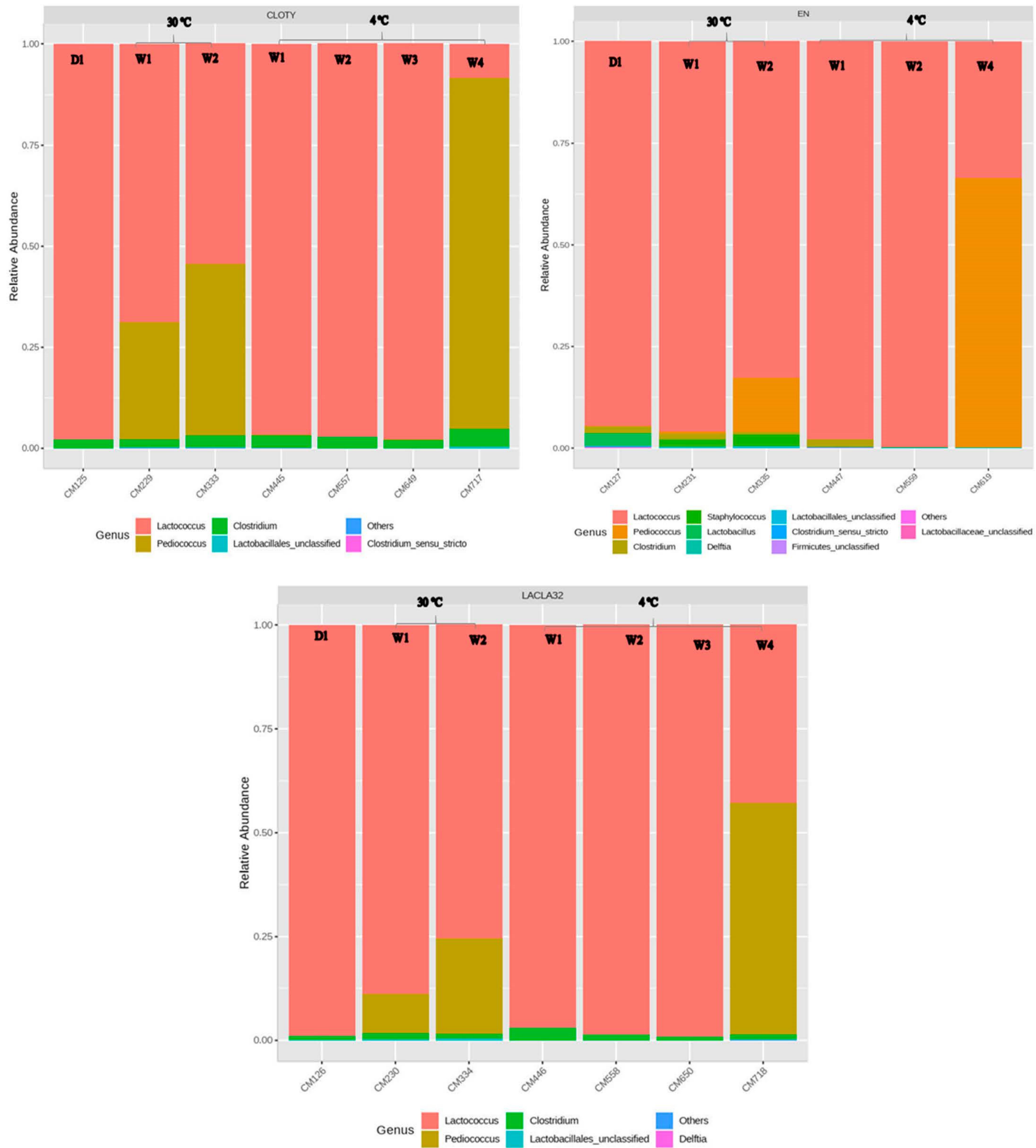

Figure 10. Relative abundance of bacterial genera, based on $16 \mathrm{~S}$ rRNA, in Cheddar cheese slurries containing C. tyrobutricum made with $2 \% \mathrm{NaCl}$. CLOTY) control, EN) Encapsulated nisin and LACLA32) protective strain treated group, stored for four weeks at $4{ }^{\circ} \mathrm{C}$ or for two weeks at $30{ }^{\circ} \mathrm{C}(\mathrm{D} 1=$ time zero).

\section{Discussion}

A great interest has developed around the use of lactic acid bacteria (LAB) as protective cultures for preserving food or to prolong their shelf life. The bio-protective activity of $\mathrm{LAB}$ is related to their ability to produce substances having biological activities at very 
low concentrations, including organic acids (acetic, lactic and propionic acid), hydrogen peroxide, diacetyl, acetaldehyde and antimicrobial peptides such as bacteriocins [29,30].

The present study aimed to assess the potential of bioprotective lactic acid cultures as well as their metabolites with antimicrobial activity (nisin) for the control of Clostridium tyrobutyricum in Cheddar-type cheese slurries.

The strains L. lactis spp. lactis CUC-H, 32 and L. lactis spp. cremoris 222 were selected to be used as a protective starter. To select the suitable ratio between the selected strains, the Pearce test was done. The results showed that the most compatible ratio was L. lactis spp. lactis CUC-H, L. lactis spp. cremoris 222 and lactis 32 at a ratio of 1:1:1.5 for a total inoculum volume of $2 \%$. A combination of a nisin-producing l. lactis spp. cremoris JSI02 and l. lactis spp. lactis $\mathrm{C} 2$ at a total inoculation volume of $6 \%(4 \% \mathrm{C} 2$ and $2 \%$ JSI02) reportedly reached a $\mathrm{pH} \leq 5.4$ in $5 \mathrm{~h}$ [31]. In addition, the combinations of l. lactis spp. cremoris and l. lactis spp. lactis and l. lactis spp. lactis biovar diacetylactis at a ratio 1.5:1.5:1 for a $2 \%$ total inoculum reportedly grew and produced nisin Z [21]. In all these cases, bacteriocin was produced during fermentation of milk. It remains to be shown whether bacteriocin production continues during cheese storage too.

The chemical composition of Cheddar cheese slurries and the effect of $\mathrm{pH}$ and salt on bacterial growth and bioactive compound production in milk has been studied [17]. Under the two $\mathrm{NaCl}$ concentrations, there is no significant effect of pHs on Lactococcus counts. The $C$. tyrobutyricum was not detected in the group treated with encapsulated nisin in the presence of $2 \%$ salt, from the second week of storage at $4{ }^{\circ} \mathrm{C}$. The addition of the protective ferment inhibited the growth of $C$. tyrobutyricuim from the second week. Similar results have been reported for four clinical isolates of Clostridium difficile $2.5 \log _{10} \mathrm{cfu} / \mathrm{mL}$ reductions from $10^{6} \mathrm{cfu} / \mathrm{mL}$ in the presence of $3.2 \mu \mathrm{g} / \mathrm{mL}$ nisin [32]. Clostridium beijerinckii at $2.2 \times 10^{5}$ spores $/ \mathrm{mL}$ reportedly failed to germinate in pasteurized ovine milk inoculated with a bacteriocin-producing strain of $L$. lactis ssp. lactis, thus preventing late blowing even after 30 days of incubation at $23^{\circ} \mathrm{C}$ [33].

The nisin production from L. lactis ssp. lactis 32 was followed up during the Cheddar slurries incubation. The production of nisin was increased gradually for all cheese groups. This is in agreement with studies of nisin $\mathrm{Z}$ produced by L. lactis biovar diacetylactis during ripening of Cheddar cheese, in which activity declined from over 300 units per $g$ to less than 30 units in six months at $7{ }^{\circ} \mathrm{C}$ [21]. On the other side, the capsules maintain stability and control the nisin release in cheese during storage. The nisin released from capsules decreased after the second week. Similar results have been obtained for liposomeencapsulated nisin $\mathrm{Z}$ during a second month of storage at $7{ }^{\circ} \mathrm{C}$ [21]. Moreover, the nisin producing L. lactis ssp. lactis INIA 415 strain delayed the late blowing defect (LBD) by seven days during ripening at $14{ }^{\circ} \mathrm{C}$ in the cheese produced from milk contaminated with $3.1 \mathrm{log}$ spores / $\mathrm{mL}$ of C. tyrobutyricum CECT 4011 spores [34]. The same inhibitory effect was observed against $C$. tyrobutyricum CECT 4011 using the L. lactis IPLA 729 strain that produces nisin- $Z$ in a combination with starter culture during the manufacturing of Vidiago cheese, a semi-hard farmhouse variety, produced in Asturias, Spain. The counts of C. tyrobutyricum were reduced by $3 \operatorname{logs}_{10}$ at nisin concentration of $1600 \mathrm{AU} / \mathrm{ml}$ compared to an increase in the control group of $3.2 \operatorname{logs} 10$ during the 30 days of storage at $12{ }^{\circ} \mathrm{C}$ [35].

The microbial ecosystem of Cheddar cheese slurries was tested, at low salt concentration $(1.3 \% \mathrm{NaCl})$. The relative abundance of Clostridium at $4{ }^{\circ} \mathrm{C}$ dropped significantly in the encapsulated nisin treated group, followed by the nisin-producing strain treated group compare to the control group. The effect of lowered salt concentration on bacterial growth in ripening cheese has been studied. In soft cheese surface-ripened for 27 days at $12{ }^{\circ} \mathrm{C}$, Pseudomonas fragi, there was an increase even at the concentration of $1.8 \% \mathrm{NaCl}$, but it was significantly lower than the growth with a concentration of $1.3 \%$ [13]. In postaging, Listeria monocytogenes contamination of Cheddar cheese, the L. monocytogenes count decreased by 0.14 to $1.48 \log _{10}$ at 0.7 and $1.8 \%$ salt concentration, respectively, during 90 days at $4{ }^{\circ} \mathrm{C}$ [36].

Artisanal cheeses collected from 11 different regions in Brazil revealed the dependence of microbial population dynamics on production conditions and subsequent processing 
steps [37]. Although LAB were always dominant, thermophile bacteria such as Streptococcus were found dominant in cheeses from the North, Cerrado and Serro regions. In cheeses from the Northeast, mesophiles (Leuconostoc) were more likely to dominate. Cheeses from the North also contained high counts of Lactobacillus fermentum. Salers cheese produced from raw milk by traditional methods on farms showed growing LAB counts on the first day of production, based on single-strand conformation polymorphism analysis, and was dominated by Lactococcus lactis, Streptococcus thermophilus, Lactobacillus pentosus and Lactobacillus plantarum after three months of ripening [38].

The metagenomic profile of Gouda cheese containing PMA showed that viable counts of starter culture strains ( 5 L. lactis cremoris, 2 L. lactis lactis and 1 Leuconostoc mesenteroides) increased until the brining step, at which point the counts dropped by 2-3 orders of magnitude, based on amplified fragment length polymorphism quantified by lineage-specific qPCR because of the differential inactivation rates. During ripening, the relative abundance of two citrate-positive L. lactis ssp. lactis, a L. lactis ssp. cremoris and a Ln. mesenteroides ssp. cremoris increased, while other strains from the same genus disappeared due to the effects of salt and low $\mathrm{pH}$ [39]. Furthermore, the Lactococcus lactis species showed the highest mean DNA coverage during ripening of semi-hard Maasdam-type cheeses after 12 days in a warm room or 37 days in a cold room. Finally, a study of bacterial dominance and richness in Cotija cheese using high-throughput $16 \mathrm{~S}$ rDNA sequencing showed that the cheeses were dominated by three genera: Lactobacillus, Leuconostoc and Weissella, followed by more than 500 non-dominant genera grouped into 31 phyla of bacteria and archaea [39].

\section{Conclusions}

To study the effectiveness of biological antimicrobial formulas in cheese, three groups of Cheddar cheese slurry were designed: a control group challenged with Clostridium tyrobutyricum spores without any protection; a similar group containing a bacteriocin-producing lactic ferment and another similar group containing encapsulated nisin. All groups included slurry made at pH 5.0 or pH 5.3 and with $1.3 \%$ or $2 \% \mathrm{NaCl}$ and stored at $4{ }^{\circ} \mathrm{C}$ or $30^{\circ} \mathrm{C}$. Clostridium tyrobutyricum was not detected in the $2 \% \mathrm{NaCl}+$ encapsulated nisin group after two weeks at $4{ }^{\circ} \mathrm{C}$. In the presence of the protective strain and $2 \% \mathrm{NaCl}$, Clostridium viable spore counts fell by $1 \log$ after one month at $4{ }^{\circ} \mathrm{C}$. Also, the bacteriocin was produced during storage at $4{ }^{\circ} \mathrm{C}$. Using classical enumeration techniques, it was shown that Lactococcus was the dominant genus during storage in all treatment cases. However, $16 \mathrm{~S}$ rRNA sequencing showed dynamics among bacteria of different genera. After four weeks at $4{ }^{\circ} \mathrm{C}$, Pediococcus become dominant in the presence of encapsulated nisin or the protective strain and $2 \%$ salt. In the encapsulated nisin group, the genus Clostridium decreased during storage at $4{ }^{\circ} \mathrm{C}$, but its $16 \mathrm{~S}$ rRNA could be detected. It was not countable using classical techniques. Finally, the classical and the molecular quantitative methods both showed that the bacteriocinproducing strain and encapsulated nisin are both able to control the growth of Clostridium in Cheddar cheese slurries.

Author Contributions: H.H. participated in the experimental design, was responsible for the laboratory analysis, data analysis and writing. D.S.-G. participated in the experimental design, and data analysis. A.G. participated in the capsules production. I.F. participated in the experimental design, and writing. All authors have read and agreed to the published version of the manuscript.

Funding: This work was supported by the government of Egypt, grant from the Natural Sciences and Engineering Research Council of Canada industrial research chair METABIOLAC (grant number IRCPJ 499946-15) and the chair partners.

Acknowledgments: We would like to thank Steven Davis for reading the manuscript and providing help in English. Annie Caron and Gaetan Bélanger for helping during cheese slurry production and analysis at the Agriculture Canada research center in St-Hyacinthe, Québec.

Conflicts of Interest: The authors declare that the research was conducted in the absence of any commercial or financial relationships that could be construed as a potential conflict of interest. 


\section{References}

1. Bermúdez, J.; González, M.J.; Olivera, J.A.; Burgueño, J.A.; Juliano, P.; Fox, E.M.; Reginensi, S.M. Seasonal occurrence and molecular diversity of clostridia species spores along cheesemaking streams of 5 commercial dairy plants. J. Dairy Sci. 2016, 99, 3358-3366. [CrossRef]

2. Gómez-Torres, N.; Garde, S.; Peirotén, Á.; Ávila, M. Impact of Clostridium spp. on cheese characteristics: Microbiology, color, formation of volatile compounds and off-flavors. Food Control 2015, 56, 186-194.

3. McSweeney, P.; Fox, P. Metabolism of residual lactose and of lactate and citrate. In Cheese: Chemistry, Physics, and Microbiology; Elsevier: Amsterdam, The Netherlands, 2004; Volume 1, pp. 361-371.

4. Klijn, N.; Nieuwenhof, F.; Hoolwerf, J.D.; van der Waals, C.; Weerkamp, A.H. Identification of Clostridium tyrobutyricum as the causative agent of late blowing in cheese by species-specific PCR amplification. Appl. Environ. Microbiol. 1995, 61, $2919-2924$. [CrossRef] [PubMed]

5. Fernández García, L.; Blanco, S.Á.; Rodriguez, F.A.R. Microfiltration applied to dairy streams: Removal of bacteria. J. Sci. Food Agric. 2013, 93, 187-196. [CrossRef] [PubMed]

6. Ávila, M.; Gómez-Torres, N.; Hernández, M.; Garde, S. Inhibitory activity of reuterin, nisin, lysozyme and nitrite against vegetative cells and spores of dairy-related Clostridium species. Int. J. Food Microbiol. 2014, 172, 70-75. [CrossRef] [PubMed]

7. Van den Berg, G.; Meijer, W.; Düsterhöft, E.-M.; Smit, G. Gouda, and related cheeses. In Cheese: Chemistry, Physics and Microbiology; Elsevier: Amsterdam, The Netherlands, 2004; pp. 103-140.

8. Lodi, R.; Stadhouders, J. The use of lysozyme to control butyric acid fermentation. Bull. Int. Dairy Fed. 1990, 251, 51-54.

9. Stadhouders, J. Prevention of butyric acid fermentation by the use of nitrate. Bull. Int. Dairy Fed. 1990, $251,40-46$.

10. D'Incecco, P.; Faoro, F.; Silvetti, T.; Schrader, K.; Pellegrino, L. Mechanisms of Clostridium tyrobutyricum removal through natural creaming of milk: A microscopy study. J. Dairy Sci. 2015, 98, 5164-5172. [CrossRef] [PubMed]

11. Fremont, S.; Kanny, G.; Nicolas, J.; Moneret-Vautrin, D. Prevalence of lysozyme sensitization in an egg-allergic population. Allergy 1997, 52, 224-228. [CrossRef]

12. Dugat-Bony, E.; Sarthou, A.-S.; Perello, M.-C.; de Revel, G.; Bonnarme, P.; Helinck, S. The effect of reduced sodium chloride content on the microbiological and biochemical properties of a soft surface-ripened cheese. J. Dairy Sci. 2016, 99, $2502-2511$. [CrossRef]

13. Appel, L.J.; Angell, S.Y.; Cobb, L.K.; Limper, H.M.; Nelson, D.E.; Samet, J.M.; Brownson, R.C. Population-wide sodium reduction: The bumpy road from evidence to policy. Ann. Epidemiol 2012, 22, 417-425. [CrossRef]

14. Cruz, A.G.; Faria, J.A.; Pollonio, M.A.; Bolini, H.M.; Celeghini, R.M.; Granato, D.; Shah, N.P. Cheeses with reduced sodium content: Effects on functionality, public health benefits and sensory properties. Trends Food Sci. Technol. 2011, 22, $276-291$. [CrossRef]

15. Reis, J.; Paula, A.; Casarotti, S.; Penna, A. Lactic acid bacteria antimicrobial compounds: Characteristics and applications. Food Eng. Rev. 2012, 4, 124-140. [CrossRef]

16. Gálvez, A.; Abriouel, H.; López, R.L.; Omar, N.B. Bacteriocin-based strategies for food biopreservation. Int. J. Food Microbiol. 2007, 120, 51-70. [CrossRef]

17. Jack, R.W.; Tagg, R.J.; Ray, B. Bacteriocins of gram-positive bacteria. Microbiol. Mol. Biol. Rev. 1995, 59, 171-200. [CrossRef]

18. Delves-Broughton, J. Natural antimicrobials as additives and ingredients for the preservation of foods and beverages. In Natural Food Additives, Ingredients and Flavourings; Elsevier: Amsterdam, The Netherlands, 2012; pp. 127-161.

19. Shin, J.M.; Gwak, J.W.; Kamarajan, P.; Fenno, J.C.; Rickard, A.H.; Kapila, Y.L. Biomedical applications of nisin. J. Appl. Microbiol. 2016, 120, 1449-1465. [CrossRef] [PubMed]

20. Verheul, A.; Russell, N.J.; Hof, R.V.T.; Rombouts, F.M.; Abee, T. Modifications of membrane phospholipid composition in nisin-resistant Listeria monocytogenes Scott. A. Appl. Environ. Microbiol. 1997, 63, 3451-3457. [CrossRef] [PubMed]

21. Benech, R.-O.; Kheadr, E.; Laridi, R.; Lacroix, C.; Fliss, I. Inhibition of Listeria innocua in cheddar cheese by addition of nisin Z in liposomes or by in situ production in mixed culture. Appl. Environ. Microbiol. 2002, 68, 3683-3690. [CrossRef] [PubMed]

22. Chi-Zhang, Y.; Yam, K.L.; Chikindas, M.L. Effective control of Listeria monocytogenes by combination of nisin formulated and slowly released into a broth system. Int. J. Food Microbiol. 2004, 90, 15-22. [CrossRef]

23. de Arauz, L.J.; AJozala, F.; Mazzola, P.G.; Penna, T.C.V. Nisin biotechnological production and application: A review. Trends Food Sci. Technol. 2009, 20, 146-154. [CrossRef]

24. Hassan, H.; Gomaa, A.; Subirade, M.; Kheadr, E.; St-Gelais, D.; Fliss, I. Novel design for alginate/resistant starch microcapsules controlling nisin release. Int. J. Biol. Macromol. 2019, 15, 1186-1192. [CrossRef]

25. Okereke, A.; Montville, T.J. Bacteriocin inhibition of Clostridium botulinum spores by lactic acid bacteria. J. Food Prot. 1991, 54, 349-353. [CrossRef]

26. Gardner-Fortier, C.; St-Gelais, D.; Champagne, C.P.; Vuillemard, J.-C. Determination of optimal conditions for $\gamma$-aminobutyric acid production by Lactococcus lactis ssp. lactis. Int. Dairy J. 2013, 32, 136-143. [CrossRef]

27. Bullard, J.; St-Gelais, D.; Turgeon, S.L. Production of set yoghurts using thermophilic starters composed of two strains with different growth biocompatibilities and producing different exopolysaccharides. Int. Dairy J. 2018, 79, 33-42. [CrossRef]

28. Desfossés-Foucault, É.; Dussault-Lepage, V.; le Boucher, C.; Savard, P.; LaPointe, G.; Roy, D. Assessment of probiotic viability during Cheddar cheese manufacture and ripening using propidium monoazide-PCR quantification. Front. Microbiol. 2012, 3, 350. [CrossRef] 
29. Davidson, P.; Cekmer, H.B.; Monu, E.; Techathuvanan, C. The use of natural antimicrobials in food: An overview. In Handbook of Natural Antimicrobials for Food Safety and Quality; Elsevier: Amsterdam, The Netherlands, 2015; pp. 1-27.

30. Silva, C.C.; Silva, S.P.; Ribeiro, S.C. Application of bacteriocins and protective cultures in dairy food preservation. Front. Microbiol. 2018, 9, 594. [CrossRef]

31. Roberts, R.F.; Zottola, E.; McKay, L. Use of a nisin-producing starter culture suitable for Cheddar cheese manufacture. J. Dairy Sci. 1992, 75, 2353-2363. [CrossRef]

32. Nerandzic, M.M.; Donskey, C.J. Activate to eradicate inhibition of Clostridium difficile spore outgrowth by the synergistic effects of osmotic activation and nisin. PLoS ONE 2013, 8, e54740. [CrossRef]

33. Garde, S.; Ávila, M.; Arias, R.; Gaya, P.; Nuñez, M. Outgrowth inhibition of Clostridium beijerinckii spores by a bacteriocinproducing lactic culture in ovine milk cheese. Int. J. Food Microbiol. 2011, 150, 59-65. [CrossRef] [PubMed]

34. Ávila, M.; Gómez-Torres, N.; Gaya, P.; Garde, S. Effect of a nisin-producing lactococcal starter on the late blowing defect of cheese caused by Clostridium tyrobutyricum. Int. J. Food Sci. Technol. 2020, 55, 3343-3349. [CrossRef]

35. Rilla, N.; Martínez, B.; Delgado, T.; Rodríguez, A. Inhibition of Clostridium tyrobutyricum in Vidiago cheese by Lactococcus lactis ssp. lactis IPLA 729, a nisin Z producer. Int. J. Food Microbiol. 2003, 85, 23-33. [CrossRef]

36. Shrestha, S.; Grieder, J.; McMahon, D.J.; Nummer, B. Survival of Listeria monocytogenes introduced as a post-aging contaminant during storage of low-salt Cheddar cheese at 4, 10, and $21^{\circ}$ C. J. Dairy Sci. 2011, 94, 4329-4335. [CrossRef] [PubMed]

37. Kamimura, B.A.; de Filippis, F.; Sant'Ana, A.S.; Ercolini, D. Large-scale mapping of microbial diversity in artisanal Brazilian cheeses. Food Microbiol. 2019, 80, 40-49. [CrossRef] [PubMed]

38. Duthoit, F.; Callon, C.; Tessier, L.; Montel, M.-C. Relationships between sensorial characteristics and microbial dynamics in "Registered Designation of Origin" Salers cheese. Int. J. Food Microbiol. 2005, 103, 259-270. [CrossRef] [PubMed]

39. Erkus, O.; de Jager, V.C.; Geene, R.T.; van Alen-Boerrigter, I.; Hazelwood, L.; van Hijum, S.A.; Kleerebezem, M.; Smid, E.J. Use of propidium monoazide for selective profiling of viable microbial cells during Gouda cheese ripening. Int. J. Food Microbiol. 2016, 228, 1-9. [CrossRef] [PubMed] 